\title{
Political Determinants of National Environmental Performance in the European Union
}

\author{
Constantin-Marius Apostoaie ${ }^{1}, \mathrm{PhD}$; Alexandru Maxim ${ }^{1}, \mathrm{PhD}$
}

\begin{abstract}
The extent to which certain elements of the political landscape affect the quality of the environment and contribute to the differences in national Environmental Performance (EP) is not well known and requires further investigation. The aim is to identify those elements of political nature which tend to affect a country's EP. The main research method consists of an OLS regression analysis where the dependent variable is the Environmental Performance Index. The explanatory variables were selected to best gauge the political landscape and are drawn from three well established datasets. The main added value of the study consists in the proposal of a new political indicator that was proven to significantly impact national EP - the environmental preference of governmental parties corrected with the degree of effectiveness of the overall government. The reason why we chose to focus on governments is that these are the main agenda setters in the EU legislative decision making process. Our research shows that effective governments composed of parties with an environmental preference are successful in improving the national EP.
\end{abstract}

Keywords: environmental performance; effective government; political party; environmental policy; European Union; environmental preference

\section{Introduction}

Environmental degradation (either in the form of pollution or mismanagement of natural resources) is a phenomenon that is not limited by geographic boundaries, yet it is more pronounced in some countries than in others. It occurs around the world, with significant and sometimes irreversible consequences on current and future generations' health and lifestyle. The degree of environmental quality also determines a country's level of attractiveness as a place to live (Esty and Porter, 2002). In this harsh context the proper designing and management of tailored environmental policies is a nation's responsibility, which must be fulfilled, not only for the protection of its citizens, but also for the safety of and moral duty towards its neighbours (Apostoaie, 2016), giving rise to the concept of 'environmental state' - which implies the management of environmental problems as 'an irreducible element of what governments actually do' (Duit et al., 2016; Sommerer and Lim, 2016). The society often looks towards their national governments for solutions to improve the quality of the environment when they consider that this is required.

Therefore, the quality of the environment is an ardent topic (or at least it should be at all levels of society) and also a growing concern for advanced, as well as developing countries. Nonetheless, this topic rose on the political agenda only after the 1960s. As environmental politics moved increasingly more into the spotlights of national governments (driven by the increasing rate of degradation or by increased public awareness of existing environmental problems), it migrated from "national to international policy arenas" (Duit, 2005: 1). 
As part of this evolution process, Fiorino (2011) identified two important waves of development: a) the $1^{\text {st }}$ wave of national programs led by the early 'pioneers' took place mainly among the western democracies; as a response to the existing environmental issues (Weidner, 2002), states such as Sweden or the USA created the appropriate institutions, enacted laws and developed the necessary administrative and technical capacity; b) the $2^{\text {nd }}$ wave occurred in the developing countries and transitional economies as a response to the World Commission on Environment and Development meeting (in 1983) and the Rio Earth Summit (in 1992); simultaneously, as environmental requirements grew, many of the $1^{\text {st }}$ wave countries adapted by changing their laws, institutions and infrastructure.

Regardless of the levels at which environmental policies are currently designed and implemented (global, regional and local authorities becoming more and more involved in managing environmental issues), national governments remain in the forefront of environmental policymaking. Moreover, they are accountable to their citizens for the environmental policies they put into practice and for the level of environmental performance they require. The environmental performance of a country is a fact given by its "ability to produce environmental public goods" (Duit, 2005).

There is currently a growing literature on the environmental performance (EP) at a national level, which aims at better explaining and understanding the phenomena (with regard to its definition, approach, main 'caretaker', ways of gauging it, determinant factors etc.). There is also an increasing body of research in the designing of indicators that capture a country's EP level. In the current study, we turn to the Environmental Performance Index (EPI), a composite indicator developed by Esty et al. (2008). Moreover, the studies which look for the influence that political factors (general descriptive state level political factors, such as level, age and quality of democracy or institutional capacity etc.) have on a country's EP level are wide raging and informative. Nonetheless, the authors have noticed that some specific variables related to politics and governmental parties may have been overlooked, as also observe by Knill et al. (2010).

The aim of this research is to identify which variables related to politics and governmental parties tend to influence the environmental performance of a country. The main research method consists of an OLS regression analysis where the dependent variable is EPI: first in its aggregated form, and then considering its two composing dimensions. The explanatory variables were selected to best capture a country's political sphere and include: a) institutional variables (describing state level politics): level of democracy, level of political corruption, government effectiveness, governmental quality; b) variables related to political parties (describing a party's ideological framework): the political party's preference towards the environment, the government's preference towards the environment, the inclination towards anti-growth politics of the major party and of the government. The study employs an innovative compound indicator which accounts for the inclination of the ,effective' government towards 'sustainable growth' and 'environmental protection' policies. Also, some economic variables were considered: GDP per capita, share of services in the economy.

The paper is structured as follows: Section 2 presents the concept of National Environmental Performance (definitions and measurements), Section 3 discusses some factors of influence for EP (focusing on political and economic aspects), Section 4 
presents the data selection and methodology, Section 5 includes the correlation analyses and regression models and Section 6 concludes and proposes future developments of the study.

\section{National Environmental Performance}

\subsection{Introductory remarks and definition}

Environmental protection is currently in need of a significant international agreement which has to be backed up by all the important global players (Apostoaie, 2016). Moreover, it must go beyond the limited results of the already defunct Kyoto Protocol which ended without a successor agreement in place (Mihai et al., 2016). The scarcity of achievements on protecting the environment at a global level is due either to the increasing reluctance of some countries to be part of important international agreements, or to the belief of other countries that economic development trumps environmental protection (by any means).

Despite their evolution and scale (as mentioned earlier), environmental policies remain nonetheless the nation-state's concern and responsibility on the long run. The flawless implementation of specific environmental policies (either at a narrow or a larger scale) will be determined mainly by national policies and their commitment, institutions, as well as administrative and technical capacity (as specified in Sommerer and Lim, 2016) attributing to national governments a vital role of genuine 'linchpins' (Fiorino, 2010). This makes the state 'the primary mode of social and political organization and decision making' (Duit, 2005: 1) as it addresses environmental degradation. As such, national public policy becomes the 'main channel for environmental quality improvement' (Michallet et al., 2015) and a state's environmental performance (either limited or significant) becomes the main output of these policies (regardless of their success or failure).

One point of view is that the environmental performance (EP) of a country is given by its 'ability to produce environmental public goods' (Duit, 2005). This makes each nationstate accountable to its citizens for the environmental policies it puts into practice and the level of environmental quality they require. Driven by the accountability towards their voters, political candidates (as future policy makers) will try to please the electorate and offer them the requested information about EP. The designated place where the society's demand of EP meets the politician's offering is the election time. This in turn is a "pivotal period since parties' commitment to platforms determines policy outcomes and political institutions aggregate citizens' preferences diversity” (Michallet et al., 2015). The existing literature with regard to national EP can be divided in two important strands, where the focus is either on policy outputs or outcomes as stated by Fiorino (2011).

\subsection{Measuring Environmental Performance}

There is also an increasing body of research in the designing and usage of indicators that best capture a country's EP level; for extensive discussions on the topic see Liu et al. (2016); Neves Almeida and García-Sánchez (2016); García-Sánchez et al. (2015); Gallego-Álvarez et al. (2014); Knill et al. (2010); Fiorino (2010). Although these indicators have progressed over time, some major deficiencies still exists (Brewer and Pojasek, 2012). Some of the most known composite indicators used to measure a country's EP level are: the Ecological Footprint (EF) and Biocapacity initially developed by Rees and 
Wackernagel (1996) - perhaps the most referenced sustainability indicator in the current literature (Liu et al., 2016); the Composite Index of Environmental Performance developed by García-Sánchez et al. (2015); the Living Planet Index developed by the World Wide Fund for Nature; the Environmental Vulnerability Index developed by the South Pacific Applied Geoscience Commission; the Environmental Degradation Index proposed by Jha and Murthy (2003); the Renewability and Energy Sustainability Index (see Gallego-Álvarez et al., 2014).

In this study, we turn to one of the most promising efforts to better capture a country's EP level, the Environmental Performance Index (EPI), derived from the earlier Environmental Sustainability Index; it is a composite indicator developed by Esty et al. (2008), who form part of a group of environmental experts at Yale University and Columbia University.

\section{Factors Influencing National Environmental Performance}

\subsection{Economic and Other Determinants of Environmental Performance}

Perhaps as important as the studies focused on defining and measuring environmental performance is the research aimed at identifying the determinant factors that can be associated with higher levels of national EP. In the process of determining what factors exert a certain influence over a country's EP level, researchers usually found their work on one of the consecrated theories related to environmental performance: the economic theory, the Ecological Modernization Theory or the Ecological Kuznets Curve Theory.

All of the above mentioned theories focus heavily on the 'economic-environment' binomial relationship (i.e., economic growth - environmental performance). Nonetheless, given the wide variations in levels of environmental performance among countries with similar economic background, researchers looked also for other possible determinant factors for such discrepancies. Among some possible determinants the literature refers to: political institutions, technical and scientific capabilities, characteristics of civil society, a nation's natural endowments and resources and international commitments (Fiorino, 2011) etc.

\subsection{Political Determinants of Environmental Performance}

The literature which looks for the influences that political factors have on a country's EP level is currently wide raging. Yet, EP's political determinants caught the scholars' attention when the mainstream theories presented earlier had "relatively little to offer when it came to understanding political aspects of environmental management" (Duit, 2005: 4).

Fiorino (2011) does a remarkable job by organizing, interpreting and assessing the existing body of literature which focuses on the effects on EP of democracies, political institutions and institutional capacity. However, almost a decade ago many studies focused on how political factors influence, for example, economic growth, the processes of democratization, or the emergence of welfare regimes, but the research topic on the variation in environmental performance and governance among states was in its infancy (Duit, 2005). 
One important strand of literature focuses in fact on the 'democracy-economy' (inter)relationship. Other political determinants which have been addressed by scholars comprise the group of institutional factors. These include (but are not limited to): presidential-executive relations, systems for election and representation, strength of multilateral governance, legislative organization, and the role of courts (Fiorino, 2010). Other institutional factors approached in the literature include the state's internal characteristics (administration effectiveness), its style of public administration (control of corruption) and political factors (political ideology), as seen in the study of GallegoÁlvarez et al. (2014).

Although an extensive body of literature exists on the relationship between a country's EP level and its general descriptive political characteristics (level, age and quality of democracy, institutional capacity etc.), the authors have noticed that some specific variables related to politics and governmental parties may have been overlooked. The work of Knill et al. (2010) also approaches this aspect to a certain degree by analysing the extent to which national policies in the highly internationalized environmental sector are influenced by the policy preferences of political parties. However, their central indicator is focused on policy outputs (i.e., the number of environmental policies adopted) rather than a country's EP level.

\section{Data and Methodology}

\subsection{The Environmental Performance Index}

The Environmental Performance Index or EPI - which will not be discussed in detail here as extensive literature already exists (e.g., Esty et al., 2008; Esty and Porter 2002; 2005; Emerson et al., 2010; Hsu et al. 2014; 2016; Gallego-Álvarez et al., 2014; Liu et al., 2016; Neves Almeida and García-Sánchez, 2016) - is "the most comprehensive and systematic effort to date to assess environmental outcomes at a country level" (Fiorino, 2011: 371). Moreover, given that this index accounts for the effects of policies adopted by a country's decision making body and captures the "environmental sustainability" concept (rather than its specific components), the resulting data allows cross-country comparisons and the values have a high frequency (being published once every two years), EPI was chosen as one of the dependent variables for this research. The construction of EPI required the equal weighting of policy issues on two overreaching environmental goals: protection of human health from environmental problems and protection of ecosystems and natural resources - see the 'Methods' section EPI's Report (Hsu et al., 2016: 26-33). Thus, two more dependent variables are considered, corresponding to Environmental Health $(\mathrm{EH})$ and Ecosystem Vitality (EV). Given the variety of years when elections took place in the EU member states (which affects the availability of data of some of the independent variables), the analysis employs the 2016 EPI (referring to data up to 2014) and the 2014 EPI (comprising data up to 2012). The 2016 edition of the index incorporates some minor changes when compared to its earlier version (thus having a limited impact on the analysis). However, as we are referring to two different years, our analysis accounts for potential errors caused by cross-period heterogeneity by considering a dummy variable: YEAR. 


\subsection{The Environmental Preference of Political Parties}

Most of the literature on cross-national comparisons regarding a nation's EP level paid little attention to the policy process itself focusing solely on the interrelations between structural-level factors and various environmental impacts (Duit, 2005: 6). Thus, there is still very limited knowledge on the "impact of ideological orientations and positions of political parties in governments and legislatures on environmental policy outputs" (Knill et al., 2010: 302). And to acknowledge these aspects is very important given that the governments are the dominant agenda-setter in the EU legislative decision making process. One thing is clear though, "parties do matter"! (Schmidt, 2002: 167-168) Besides, there are studies which clearly point that governmental parties (parties forming the government) deliver those policies promised in their platforms during election campaigns (e.g., McDonald and Budge, 2005). It can hence be expected that the positions of parties within the governments should translate (at least to some extent, from our point of view) into policy outputs (Knill et al., 2010).

We presume that a party's 'weight' within the government (given by the share of seats) offers it a certain degree of power to negotiate and translate into practice the policy proposals presented in the campaign agenda. A similar approach is that of Gross and Sigelman (1984) and Cusack (1997) who propose the 'centre of gravity' which allows for estimating the left-right overall position of a government. Moreover, we believe that each government has a certain degree of government effectiveness when applying its policies meaning that not all policy proposals translate 100\% into the desired results (Government Effectiveness - GE).

Table 1: Political variables related to environmental preference of parties and government

\begin{tabular}{|c|c|c|c|}
\hline Indicator & Explanation & Formula & Source \\
\hline $\begin{array}{l}\text { EPMP / } \\
\text { SGMP }\end{array}$ & $\begin{array}{l}\text { Environmental Preference / } \\
\text { Sustainable Growth } \\
\text { inclination of the major party } \\
\text { (which holds the most seats } \\
\text { in the parliament) }\end{array}$ & $\begin{array}{l}=E P_{m} /=S G_{m} ; \\
\text { where } E P_{m} \text { and } S G_{m} \text { are the share of } \\
\text { sentences devoted to EP or SG }\end{array}$ & CMD \\
\hline $\begin{array}{l}\text { EPG / } \\
\text { SGG }\end{array}$ & $\begin{array}{l}\text { Environmental Preference of } \\
\text { the Government } \\
\text { Sustainable Growth } \\
\text { inclination of the } \\
\text { Government }\end{array}$ & $\begin{array}{l}=\sum_{i=1}^{n} E P_{i} \times W_{i} /=\sum_{i=1}^{n} S G_{i} \times W_{i} \\
\text { where } E P_{i} \text { and } S G_{i} \text { are the share of } \\
\text { sentences devoted to EP or SG by each } \\
\text { party forming the government and } W_{i} \text { is } \\
\text { the share of seats of each party in the } \\
\text { government }\end{array}$ & CMD \\
\hline $\begin{array}{l}\text { EPGeff } \\
\text { / } \\
\text { SGGeff }\end{array}$ & $\begin{array}{l}\text { EPG / SGG adjusted with } \\
\text { the government effectiveness } \\
\text { indicator }(\mathrm{GE})\end{array}$ & $\begin{array}{l}=\sum_{i=1}^{n} E P_{i} \times W_{i} \times G E_{i} \\
\text { where } G E_{i} \text { is the } G E \text { level of each } \\
\text { governmental party }\end{array}$ & $\begin{array}{l}\text { CMD, } \\
\text { QGSD }\end{array}$ \\
\hline
\end{tabular}

The party-level data is drawn from the Comparative Manifesto Database (CMD), one of the most comprehensive cross-national dataset for observation of parties' political platforms (Volkens et al., 2016). One variable considered in this dataset accounts for percentage of sentences devoted by each party to topics that are explicitly related to 'environmental protection' (Environmental Preference of Parties - EPP). Another variable takes into consideration the share of manifestos' content devoted to 'anti-growth economy' politics 
targeting sustainable economic development (Sustainable Growth measures proposed by each Party - SGP).

Other data sources are include the World Data Bank - WDB (World Bank, 2016) and Quality of Government Standard Dataset - QGSD (Teorell et al., 2016).

Summarizing, some of the independent variables are presented in Table 1.

\subsection{Other Political Determinants of Environmental Performance}

Other important political determinants (referring to democracy and institutional characteristics) that we presume to have an impact on a country's EP level are:

a) Political Corruption (PC) - measures the corruption level by taking the average of: public sector, executive, legislative and judicial corruption; this index runs from less corrupt (0) to more corrupt (1).

b) Democracy Level (DL) - includes, among other 4 variables, the degree of functioning of the government; the index ranges from the least democratic (0) to the most democratic (10) country.

c) Government Effectiveness (GE) - combines into a single grouping the government's commitment towards proposed policies, the quality of public service provision, the quality of the bureaucracy, the competence of civil servants and the independence of the civil service from political pressures; the values range from very weak (approximately -2.5) to very strong (approximately 2.5) governance performance.

d) Government Quality $(G Q)$ - combines into a single grouping the mean values of the International Country Risk Guide variables on 'Corruption', 'Law and Order' and 'Bureaucracy Quality'; the index runs from lower (0) to higher (1) quality of government. All the values for the above mentioned indicators are extracted from QGSD and WDB. As the literature already shows, democracy and institutional factors are important in the policy making process (Sommerer and Lim, 2016; Michallet et al., 2015; Gallego-Álvarez et al., 2014; Fiorino, 2011; Esty et al., 2008 and others). Effective governance, the democratic process and institutional capacity play an important role in addressing environmental issues and influencing a country's EP level.

\subsection{Economic Variables}

As showed by the existing literature, the gross domestic product (GDP) per capita plays a fundamental role in a country's EP level (also heighted in the mainstream theories); this is more obvious when environmental performance is measured by EPI and in its components, especially environmental health (Gallego-Álvarez et al., 2014). Thus, in the current analysis we account for the changes that the GDP per capita has on national EP. Our analysis uses the logarithmic values of GDP in order to avoid problems of heteroscedasticity.

Moreover, it is already known that the economic development process might cause an increase in ecological problems, mainly through externalities emerging from industrial production (Knill et al., 2010). As such, we consider that an economy oriented more towards services has bigger chances of being environmental friendly, i.e. has higher EP levels. For this reason we consider another economic variable: SERV (share of the economy that stems from services measured as \% of GDP). The data for both variables is extracted from WDB. 


\subsection{Data selection}

The geographical focus of our study is on the European Union, given the common commitment of the bloc towards sustainable development and environmental protection (as demonstrated by its climate and energy package, as well as several other directives and standards for trade and business development). Significant economic disparities do exist between the 28 countries, but these are somewhat limited (i.e. 25 out of 28 states have a GDP per capita between +/-65\% of the EU average, World Bank, 2016). This means that the traditionally observed link between GDP and EPI may not apply in the case of our analysis, considering the limited size and relative homogeneity of the sample.

The data for the dependant variables (EPI and its two components EH and EV) covers all 28 EU states, but the CMD data for political and electoral variables is deficient in some cases. For example, the latest political data for Austria is from the elections held in 2008, while for Malta it is 1998. Due to this issue, these two countries were not included in the analysis, resulting in a total sample size of 26 states.

Furthermore, parliamentary elections are held periodically (usually every four years), and the distribution of electoral years varies across the EU. Our assumption is that, in order to observe actual environmental policy implementation and consequent results (leading to a change in the EPI value), it is necessary that at least twelve months pass from the time that the election took place and a new government was put in place. As the EPI values are published once every two years (e.g. 2012 and 2014), our analysis includes both the 2014 EPI value (for countries which had their elections in 2010 or 2011), as well as the 2016 EPI value (for countries which had their elections in 2012 or 2013).

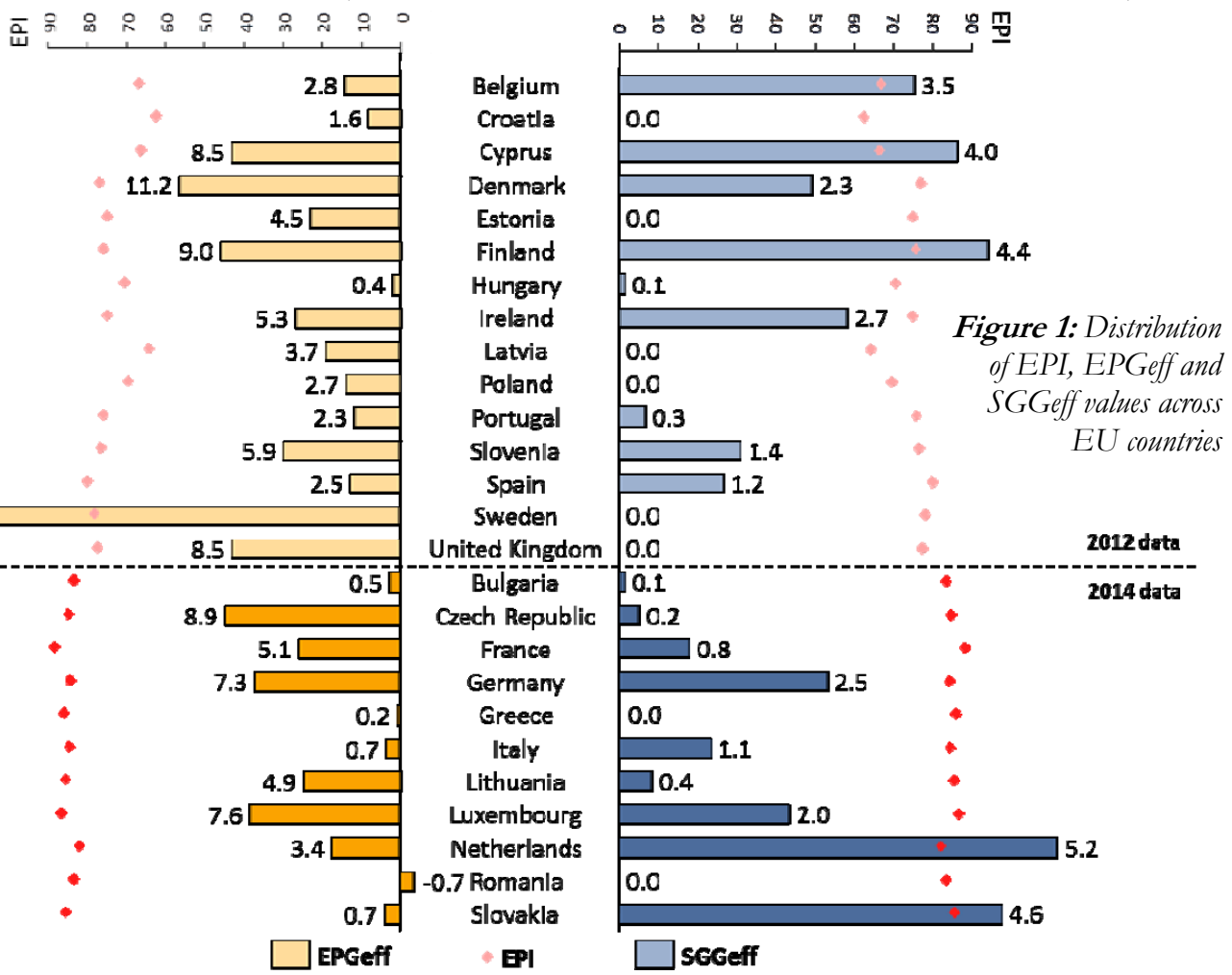

Published by ECSDEV, Via dei Fiori, 34, 00172, Rome, Italy 
Figure 1 illustrates the resulting values for the EPGeff and the SGGeff (calculated using the approach presented in Table 1) for all 26 countries, as well as the corresponding EPI values. As discussed above, the data is for 2012 and 2014 respectively, depending on the parliamentary election year.

With regard to EPGeff, all EU governments are oriented (with varying degrees of intensity) towards proposing measures of protecting the environment that are likely to have been effectively put into practice. $58 \%$ of the EPGeff values fit within the $+/-\sigma$ interval of 1.33-7.67 (excluding the two extreme outliers of Sweden and Romania). The notable exceptions in the distribution are Sweden, with a value of 21.4 and Romania, which is the only EU country that has a negative value for EPGeff. This is due to the negative sign of the GE variable, which is interacted with EPG. The result is somewhat surprising given the overall positive trend of economic development and improvements in public services and bureaucracy over the last few years, but the value is similar to neighbouring countries.

In the case of SGGeff, almost half of the countries in the sample (over $46 \%$ ) have a value equal or close to zero. This means that the share of policy proposals strictly devoted to anti-growth economy (i.e. trilateral sustainable development) are less popular across EU member states, especially in Eastern Europe, while mono-dimensional and bidimensional policies (focusing on economy, environment and/or social aspects) are more popular.

It is difficult to visually identify any relationship between EPI and the two predictor variables (EPGeff and SGGeff), as seen in Figure 1. This provides an additional argument for the necessity to perform a detailed analysis of the potential connection between EP and political determinants. Overall, the values of EPI do not fluctuate significantly across countries (as opposed to EPGeff or SGGeff). This may be an indirect result of being part of the European Union, which imposes strict and uniform standards of environmental quality across member states.

\section{Results}

\subsection{Correlations between EP and Various Political and Socio-Economic Determinants}

In order to perform the regression analysis, we first looked at the correlations between the dependent variables and the full set of predictors mentioned in Section 4. Several other variables were initially included in the analysis (e.g. right-left orientation of the government, political concentration factor, level of democracy, total environmental tax revenues, political stability, adjusted net savings - an indicator which accounts for the wellbeing of the individual and should reflect the environment dimension as stated in Percic and Apostoaie (2016), OECD membership, mean years of schooling of adults, gross enrolment in tertiary education), based on the results observed in previous studies applied at a global level. The nature of the relationships observed between EPI, EH, EV and the independent variables suggests that the Spearman's rho coefficient should be used. Table 2 illustrates the results of the analysis and highlights the relationships which are significant at levels between 0.00-0.10. 
Table 2: Correlations of EPI, EH and EV with political and economic determinants GE SGMP EPMP SGG EPG SGGeff EPGeff DL PC GQ $\operatorname{lnGDP}$ SERV YEAR

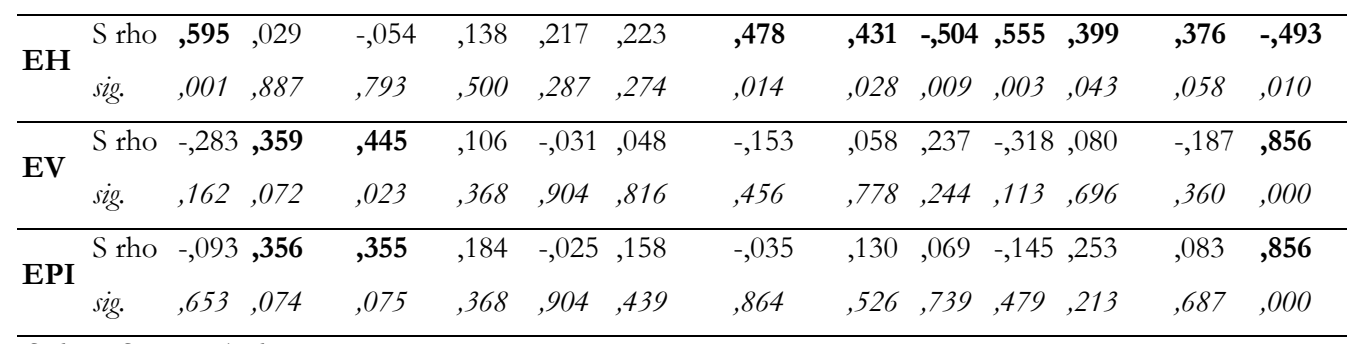

S rbo $=$ Spearman's rho

As seen in Table 2 most of the predictors are correlated with one or more of the dependants. The additional variables mentioned above are not included in Table 2 given the lack of statistical significance of the correlations. SGG, EPG and SGGeff are the only 'core variables' of the study which also do not show a significant correlation with the dependants. The direction of the significant correlations fits the generally accepted theory (e.g. direct relationship between EP and GDP, GE, GQ and inverse relationship with $p c$ ). The strength of the relationship varies between medium and strong.

Some of the more interesting results concern the dummy variable $Y E A R$ (with a value of 0 for EPI 2012 and 1 for EPI 2014), which shows a strong or very strong correlation with all three dependants. In addition, there is an inverse relationship between $Y E A R$ and $E H$, meaning that scores for environmental health were generally higher in 2012. The results of the analysis concerning YEAR suggest that including the dummy variable in the subsequent analysis is highly recommended in order to avoid potential errors related to the cross-period heterogeneity.

\subsection{Regression Models}

The main research method consists of an OLS regression analysis where the dependent variable is EPI: first jointly, and then considering its two composing dimensions ( $\mathrm{EH}$ and $\mathrm{EV})$. The predictor variables included in the analysis have been identified in Section 4: GE, SGMP, EPMP, SGG, EPG, SGGeff, EPGeff, DL, PC, GQ, $\ln G D P, S E R V, Y E A R$. After conducting preliminary analyses to ensure that the assumptions of the regression models are not violated, the following results were obtained:

Table 3: Regression models for $E H$ and $E V$

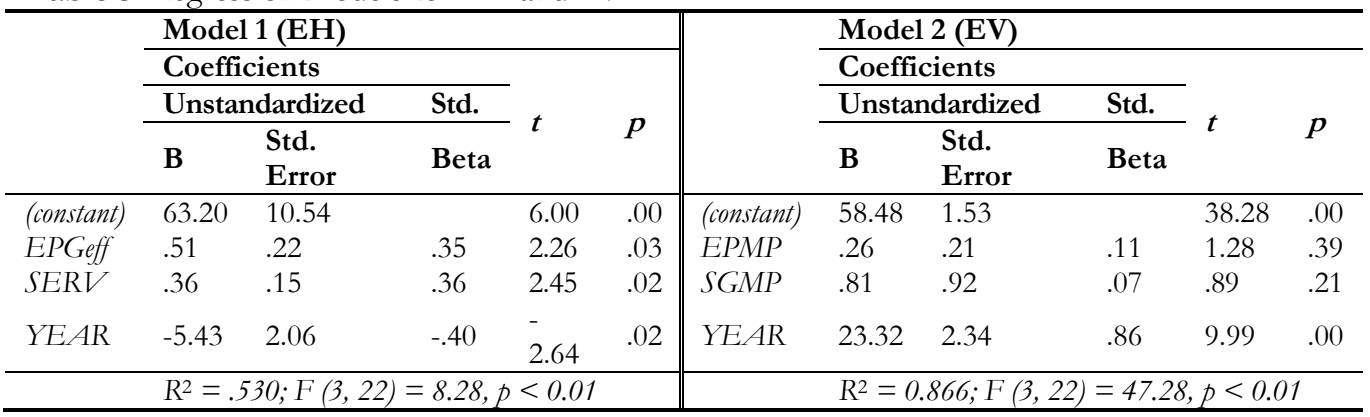


The first model explains $53 \%$ of the variance of $E H$ and all variables have statistically significant coefficients. Thus, the environmental orientation of governmental parties (interacted with the effectiveness of the government) can be used to predict the value of $\mathrm{EH}$, as expected when this indicator was proposed. The model does not explain a large part of the variance, but the signs of the coefficients are correct from a theoretical standpoint and the overall result is statistically significant. Model 1 also confirms that a higher contribution of services in the economy results in a better level of environmental health.

The second model explains close to $87 \%$ of the variance of $E V$, but, while the model itself is significant, the coefficients of EPMP and SGMP are not. This may be the result of the small sample size, which does not meet the recommended minimum of having at least 15 cases for each independent variable (Stevens, 1996). In fact, EV has proven to be difficult to predict using political and socio-economic variables, as illustrated in the existing literature (Gallego-Álvarez et al., 2014).

Finally, with regard to EPI, our first iteration of the regression produced Model 3a, which is significant and explains $68 \%$ of the variance. However, the coefficients of the predictors are not significant. For this reason, a trial and error approach was used, testing various combinations of the proposed predictors, in order to identify a better alternative. This approach allowed us to identify the relationship illustrated in Model 3b, which explains $73 \%$ of the variance, is statistically significant and includes the proposed EPGeff indicator (which also has a statistically significant coefficient). Thus, we are able to confirm our expectation that the environmental performance of a nation-state is positively influenced by an effective and environmentally oriented government.

Table 4: Regression models for EPI

\begin{tabular}{|c|c|c|c|c|c|c|c|c|c|c|c|}
\hline & \multicolumn{5}{|c|}{ Model 3a (EPI) } & & \multicolumn{5}{|c|}{ Model 3b (EPI) } \\
\hline & \multicolumn{3}{|c|}{ Coefficients } & \multirow{3}{*}{$t$} & \multirow[b]{3}{*}{$p$} & & \multicolumn{3}{|c|}{ Coefficients } & \multirow{3}{*}{$t$} & \multirow[b]{3}{*}{$p$} \\
\hline & \multicolumn{2}{|c|}{ Unstandardized } & \multirow{2}{*}{$\begin{array}{l}\text { Std. } \\
\text { Beta }\end{array}$} & & & & \multicolumn{2}{|c|}{ Unstandardized } & \multirow{2}{*}{$\begin{array}{l}\text { Std. } \\
\text { Beta }\end{array}$} & & \\
\hline & B & $\begin{array}{l}\text { Std. } \\
\text { Error }\end{array}$ & & & & & B & $\begin{array}{l}\text { Std. } \\
\text { Error }\end{array}$ & & & \\
\hline (constant) & 72.07 & 1.30 & & 55.34 & .00 & (constant) & 70.25 & 1.53 & & 45.87 & .00 \\
\hline EPMP & .09 & .18 & .06 & .48 & .63 & EPGeff & .38 & .18 & .24 & 2.10 & .05 \\
\hline SGMP & .54 & .78 & .09 & .70 & .50 & & & & & & \\
\hline$Y E A R$ & 11.61 & 1.99 & .77 & 5.83 & .00 & YEAR & 13.27 & 1.70 & .88 & 7.80 & .00 \\
\hline & \multicolumn{5}{|c|}{$\mathrm{R}^{2}=.684 ; \mathrm{F}(3,22)=15.87, p<0.01$} & & \multicolumn{5}{|c|}{$\mathrm{R}^{2}=0.726 ; \mathrm{F}(3,22)=30.40, p<0.01$} \\
\hline
\end{tabular}

It is likely that, by expanding the sample of countries, some of the initially proposed variables (such as those referring to education, GDP, adjusted net savings, corruption etc.) may prove to be correlated with EP and could be included in revised regression models. The next logical step is to expand the analysis to include other regions of the globe, which should be significantly different from Europe, both in terms of political context and environmental orientation. 


\section{Conclusions}

The findings reveal the direction and strength of some political and economic determinant factors on a country's environmental performance.

The main added value of the study consists in the proposal of a new political indicator that was proven to significantly impact national environmental performance - the environmental preference of governmental parties corrected with the degree of effectiveness of the overall government. The reason why we chose to focus on governments is that these are the main agenda setters in the EU legislative decision making process. This means that looking at ruling parties rather than majority parties (as was the case in previous studies) is likely to provide a better prediction of actual environmental policy implementation. What sets apart EPGeff from the "governments' centre of gravity on the environmental policy dimension" proposed by Knill et al. (2010) is our inclusion, in the indicator, of the 'Government Effectiveness' component which accounts for the government's ability to actual implement proposed policies (among others).

The results show that the environmental preference of political parties in effective governments have a significant impact on EP and translate, to a certain degree, to successful environmental policy implementation. As expected, the contribution of services to the overall economy also has a direct impact on improving EP. Although, not statistically significant, we expect that future research will find, as was the case with previous studies, a relationship between EP and GDP, adjusted net savings and various social and economic variables.

In addition to extending the sample size to include a larger and more heterogeneous group of countries, we will seek to utilize a common reference year for EPI. The proposed approach is to perform the analysis on clusters of countries for which a certain edition of EPI applies (e.g. EPI 2014, which refers to data up to 2012, for countries that held elections between 2010-2011). This would eliminate the impact of the cross-period heterogeneity within the cluster (which we discovered has a highly significant impact on the analysis).

Another important addition to the analysis could be the introduction of an indicator that accounts for the impact of non-governmental parties on the EP of the country. This would depend on the political openness of the governmental parties and on the negotiating power of the opposition.

Finally, a future development of the study could include time series or panel data analyses to determine causal relationships between political, economic and social variables and national environmental performance.

Although the European Union is a key global player which contributes to the international efforts of promoting environmental protection, it has nonetheless limited options of achieving this desideratum by itself. One possible solution for the EU is to impose best practices and regulations at an internal level, supported by the relatively high values of EPI, and then promote them with the hope that these will serve as a benchmark or positive example for the rest of the world (Mihai et al., 2016). Another scenario implies that EU promotes more effective environmental governance in countries that wish to embrace sustainable development and incorporate it into their 
legislation - an aspect included in the $7^{\text {th }}$ Environmental Action Programme, the basis of the current EU policy up to 2020 as well as in the United Nations Sustainable Development Goals.

\section{Acknowledgements}

This work is partially supported through the UAIC Grant for Young Researchers competition of the Alexandru Ioan Cuza University of Iaşi, Romania (Grant registration number: GI-2015-24). The POSCCEO 2.2.1, SMIS-CSNR 13984-901, No. 257/28.09.2010 Project, CERNESIM, is also gratefully acknowledged for the infrastructure used in this work.

\section{References}

Apostoaie, C.-M. (2016) Environmental policy concerns within the EaP, EURINT International Conference 2016 “The Eastern Partnership under strain - time for a rethink?". Iasi (Romania): Centre for European Studies (Alexandru Ioan Cuza University).

Brewer, A. S. \& Pojasek, R. B. (2012) "Assessing Environmental Sustainability Performance at the National Level: Leading Indicators Can Help". Environmental Quality Management, Vol. 22, No. 2, pp. 33-47.

Cusack, T. R. (1997) "Partisan politics and public finance: Changes in public spending in the industrialized democracies, 1955-1989". Public Choice, Vol. 91, No. 3, pp. 375-395.

Duit, A. (2005) Understanding Environmental Performance of States: An Institution Centered Approach and Some Difficulties, [Lecture]. Göteborg University, unpublished.

Duit, A., Feindt, P. \& Meadowcroft, J. (2016) "Greening Leviathan: the rise of the environmental state?". Environmental Politics, Vol. 25, No. 1, pp.

Emerson, J., Esty, D. C., Levy, M. A., Kim, C. H., Mara, V., de Sherbinin, A. \& Srebotnjak, T. (2010) Environmental performance index. New Haven, CT: Yale Center for Environmental Law and Policy.

Esty, D., Levy, M. A., Kim, C. H., de Sherbinin, A., Srebotnjak, T. \& Mara, V. (2008) Environmental Performance Index. New Haven: Yale Center for Environmental Law and Policy.

Esty, D. \& Porter, M. E. (2002) Ranking National Environmental Regulation and Performance: A Leading Indicator of Future Competitiveness?, in Porter, M. E., Sachs, J. D., Cornelius, P. K., McArthur, J. W. \& Schwab, K. (eds), The Global Competitiveness Report 2001-2002. New York: Oxford University Press, 78-101.

Esty, D. \& Porter, M. E. (2005) "National Environmental Performance: An Empirical Analysis of Policy Results and Determinants". Environment and Development Economics, Vol. 10, pp. 391-434.

Fiorino, D. J. (2010) Explaining National Environmental Performance: What Do We Know and What Should We Learn? Working Paper Series. Available online: https://www.american.edu/spa/cep/upload/Explaining_National Environmental Performanceworking-paper.pdf [Accessed June 5th, 2016].

Fiorino, D. J. (2011) "Explaining national environmental performance: approaches, evidence, and implications". Policy Sciences, Vol. 44, No. November, pp. 367-389.

Gallego-Álvarez, I., Vicente-Galindo, M. P., Galindo-Villardón, M. P. \& Rodríguez-Rosa, M. (2014) "Environmental Performance in Countries Worldwide: Determinant Factors and Multivariate Analysis". Sustainability, Vol. 6, pp. 7807-7832.

García-Sánchez, I.-M., Almeida, T. A. d. N. \& Camara, R. P. d. B. (2015) "A proposal for a Composite Index of Environmental Performance (CIEP) for countries". Ecological Indicators, Vol. 48, pp. 171-188.

Gross, D. A. \& Sigelman, L. (1984) "Comparing Party Systems: A Multidimensional Approach". Comparative Politics, Vol. 16, No. 4, pp. 463-479.

Hsu, A., Alexandre, N., Cohen, S., Jao, P., Khusainova, E. \& al., e. (2016) 2016 Environmental Performance Index. New Haven, CT: Yale University.

Hsu, A., Emerson, J., Levy, M., de Sherbinin, A., Johnson, L., Malik, O., Schwartz, J. \& Jaiteh, M. (2014) 2014 Environmental Performance Index. New Haven, CT: Yale Center for Environmental Law \& Policy. 
Jha, R. \& Murthy, K. V. B. (2003) "An inverse global environmental Kuznets curve". Journal of Comparative Economics, Vol. 31, No. 2, pp. 352-368.

Knill, C., Debus, M. \& Heichel, S. (2010) "Do parties matter in internationalised policy areas? The impact of political parties on environmental policy outputs in 18 OECD countries, 1970 2000". European Journal of Political Research, Vol. 49, No. 3, pp. 301-336.

Liu, X., Liu, G., Yang, Z., Chen, B. \& Ulgiati, S. (2016) "Comparing national environmental and economic performances through emergy sustainability indicators: Moving environmental ethics beyond anthropocentrism toward ecocentrism". Renewable and Sustainable Energy Reviews, Vol. 58, pp. 15321542.

McDonald, M. D. \& Budge, I. (2005) Elections, parties, democracy: Conferring the median mandate. Oxford: Oxford University Press.

Michallet, B., Gaeta, G. L. \& Facchin, F. (2015) "Greening up or not? The determinants of political parties' environmental concern: an empirical analysis based on European data (1970-2008)". FEEM Working Paper, Vol. 25, pp. 1-33.

Mihai, C., Apostoaie, C.-M. \& Maxim, A. (2016) Voice of the Students: How can the EU take the global lead on tackling climate change?, EURINT International Conference 2016 "The Eastern Partnership under strain - time for a rethink?”. Iasi (Romania): Centre for European Studies (Alexandru Ioan Cuza University).

Neves Almeida, T. A. d. \& García-Sánchez, I.-M. (2016) "A comparative analysis between composite indexes of environmental performance: An analysis on the CIEP and EPI". Environmental Science \& Policy, Vol. 64, pp. 59-74.

Percic, S. \& Apostoaie, C.-M. (2016) "A Critical Review of the Most Relevant Welfare Indicators from an Environmental Perspective". "Ovidius” University Annals, Economic Sciences Series, Vol. 16, No. 1, pp. 223-230.

Rees, W. \& Wackernagel, M. (1996) Our Ecological Footprint: Reducing Human Impact on the Earth. Gabriola Island, BC: New Society Publishers.

Schmidt, M. G. (2002) The impact of political parties, constitutional structures and veto players on public policy, in Keman, H. (ed), Comparative democratic politics: A guide to contemporary theory and research London: SAGE Publications Ltd. , 166-184.

Sommerer, T. \& Lim, S. (2016) "The environmental state as a model for the world? An analysis of policy repertoires in 37 countries". Environmental Politics, Vol. 25, No. 1, pp. 92-115.

Stevens, J. (1996) Applied Multivariate Statistics for the Social Sciences, 3rd edition. Mahwah, NJ, USA: Lawrence Erlbaum.

Teorell, J., Dahlberg, S., Holmberg, S., Rothstein, B., Khomenko, A. \& Svensson, R. (2016) The Quality of Government Standard Dataset, version Jan16. (University of Gothenburg) Created online: http://www.qog.pol.gu.se

Volkens, A., Lehmann, P., Matthieß, T., Merz, N., Regel, S. \& Werner, A. (2016) The Manifesto Data Collection. Manifesto Project (MRG / CMP / MARPOR). (Berlin)

Weidner, H. (2002) "Capacity-building for ecological modernization: Lessons from cross-national research". American behavioral scientist, Vol. 45, No. 9, pp. 1340-1368.

World Bank (2016) World Development Indicators. (Washington, DC) Created online: http://databank.worldbank.org/data/home.aspx 